Research Article

\title{
Identification of the bacterial isolates in neonatal septicaemia and their antimicrobial susceptibility in a tertiary care hospital in Uttarakhand, India: a retrospective study
}

\author{
Neerul Pandita ${ }^{1}$, Sanober Wasim ${ }^{1}$, Novneet Kumar Bhat ${ }^{1}$, Vipan Chandra ${ }^{1}$, Barnalli Kakati ${ }^{2}$
}

\author{
${ }^{1}$ Department of Pediatrics, SRHU, Jolly Grant, Doiwala, Dehradun, Uttarakhand, India \\ ${ }^{2}$ Department of Microbiology, SRHU, Jolly Grant, Doiwala, Dehradun, Uttarakhand, India
}

Received: 24 November 2015

Accepted: 17 December 2015

\author{
*Correspondence: \\ Dr. Neerul Pandita, \\ E-mail: panditaneerul@gmail.com
}

Copyright: () the author(s), publisher and licensee Medip Academy. This is an open-access article distributed under the terms of the Creative Commons Attribution Non-Commercial License, which permits unrestricted non-commercial use, distribution, and reproduction in any medium, provided the original work is properly cited.

\begin{abstract}
Background: Neonatal sepsis refers to systemic bacterial infection documented by positive blood culture in the first four weeks of life and is one of the four leading causes of neonatal mortality and morbidity in India. This study was a retrospective study to identify the bacterial isolates in neonatal septicaemia and their antimicrobial susceptibility in a tertiary care hospital in Uttarakhand, India from January 2013 to June 2015.

Methods: Blood culture in newborns with clinical sign of septicaemia was retrospectively studied. Antimicrobial susceptibility testing was performed by Kirbuay -bauer disc diffusion susceptibility method in accordance to clinical laboratory standard institute guidelines (CLSI).

Results: $10.3 \%(124 / 1200)$ cases of septicaemia could be confirmed by blood culture. Of these Gram negative could be isolated in $(62 \%)$ of cases and $(38 \%)$ were of gram positive isolates. Kliebsiella was the predominant pathogen $(42.8 \%)$ among the gram negative pathogens followed by E coli $(18.1 \%)$. CONS $(57.4 \%)$ was the predominant gram positive pathogen. Of the Gram positives isolates $6 \%$ were methicillin resistant S.aureus (MRSA). Polymyxin $(77.8 \%)$ and tigecycline $(72 \%)$ were most effective drugs against gram negative isolates were as gram positive organisms showed maximum sensitivity to vancomycin (90\%) and linezolid (87\%).

Conclusions: This study highlights the growing resistance to commonly used antibiotics; ampicillin, penicillin, ceftriaxone and ceftazidime and also highlights the importance of kleibsiella and Staphylococcus aureus as principal organism responsible for neonatal sepsis in tertiary care settings.
\end{abstract}

Keywords: Septicaemia, Neonate, Resistance, Antibiotics, Drugs

\section{INTRODUCTION}

Neonatal sepsis refers to systemic bacterial infection documented by positive blood culture in the first four weeks of life and is one of the four leading causes of neonatal mortality and morbidity in India. ${ }^{1-3}$ It contributes to be a major problem for neonates in neonatal intensive care units all over the world. Infection rates are standard indicators of quality and safety in all healthcare settings all over the world. The challenge of infection control policies and procedures is always to decrease the frequency of health care associated infection (HAI). Consequently determining infection rates through a surveillance program is central step in both identifying problems and evaluating the implementation of any program. ${ }^{4}$ Healthcare associated infections are associated with increased morbidity, mortality, and economic burden either direct or indirect. ${ }^{5}$ 
Neonatal infection can be acquired vertically from birth canal or environmentally due to lack of health care facilities. Signs and symptoms of neonatal infection are often nonspecific and the rates of hospital septicemia operating with both prematurity and low birth weight are increasing. Newborns are devoiced of efficient structural barriers, of a protective endogenous microbial flora and of a mature immune system. Premature and growth restricted babies in particular who are admitted in NICU are under profound physiological instability and are frequently exposed to therapeutic interventions associated with infectious complications such as invasive procedures and broad spectrum antibiotics.

Neonatal sepsis is broadly divided into two types according to age of onset. Early onset sepsis ( $<72$ hours) and late onset sepsis ( 72 hours to 28 days). It is caused by a variety of gram negative and gram positive bacteria as well as sometimes yeasts. The spectrum of organism that causes neonatal sepsis changes over time and varies from region to region. This is due to the changing pattern of antibiotic use and changes in lifestyle. The prevalence of bacterial profile of blood culture and their susceptibility pattern in an area provide guidance to start empirical treatment which is the cornerstone in the management of sepsis.

Therefore this study is undertaken to determine the profile and antibiotic sensitivity pattern of isolate in case of neonatal sepsis.

\section{METHODS}

All newborn aged 0 to 28 days admitted in NICU from January 2013 to June 2015 with one or more signs and symptoms suggestive of sepsis with or without risk factor for sepsis in whom blood culture or any other culture was sent were recruited in the study. Empirical antibiotic used and site of sepsis was retrieved from the data. Healthy term neonates having transient tachypnea of newborn, those with gross congenital anomalies and those undergone major surgical intervention prior to sending blood culture were excluded from the study. Institutional ethics committee clearance was taken. Neonate complete history, examination and investigation were recorded according to the Performa and the subjects were divided into culture negative and culture positive cases. Antimicrobial susceptibility testing was performed by Kirby -Bauer disc diffusion susceptibility method in accordance to Clinical Laboratory Standards Institute (CLSI) guidelines6.The blood culture specimen was processed in BACTEC 9120. Inoculated blood culture media was considered negative if there was no growth after continuous incubation for upto 5 days, the data was expressed in terms of frequency and percentage. Chi square test was used to check the test of proportion. The results were analyzed using the statistical package, SPSS version 14.

\section{RESULTS}

During the two and a half year period starting from January 2013 to June 2015 a total of 1200 blood samples were sent from septicaemia neonates, out of which 124 blood cultures turned out to be positive giving an overall prevalence rate of $10 \%$. Detailed aetiology of Gram negative and gram positive bacilli is provided in Table 1 and Table 2 respectively. Among culture positive cases, Gram negatives were the commonest organism found $(62 \%)$. The prevalence rate of gram positive isolates was (38\%). Out of Gram negative isolates Klebsiella was the commonest organism found $42.8 \%$, followed by $E$ coli (18.10\%), and Acinetobacter (10.3\%). In Gram positive organisms CONS $(68 \%)$ was the most common isolate followed by Staphylococcus aureus (21.2\%). Of total gram positive isolate MRSA was found to be (6.3\%).

Table 1: Distribution (frequency) of bacterial isolates from newborns with clinically suspected cases of septicaemia.

\begin{tabular}{|ll|l|}
\hline $\begin{array}{l}\text { Isolate } \\
(\mathbf{n = 7 7 )}\end{array}$ & $\begin{array}{l}\text { Distribution } \\
\text { (frequency) }\end{array}$ & $\begin{array}{l}\text { Percentage } \\
(\%)\end{array}$ \\
\hline Klebsiella species & 33 & 42.8 \\
\hline Klebsiella pneumonia & 25 & \\
\hline Klebsiella oxytoxa & 8 & 18.1 \\
\hline Escherichia species & 14 & 10.3 \\
\hline Acinetobacter species & 8 & \\
\hline Acinetobacter baumannii & 5 & 9 \\
\hline Acinetobacter lwofii & 3 & 9 \\
\hline Enterobacter species & 7 & 5.10 \\
\hline Citrobacter species & 7 & 3.8 \\
\hline Pseudomonas & 4 & 1.3 \\
\hline $\begin{array}{l}\text { Non fermenting gram } \\
\text { negative Bacillus }\end{array}$ & 3 & \\
\hline $\begin{array}{l}\text { Unidentified gram } \\
\text { negative Bacillus }\end{array}$ & 1 & \\
\hline
\end{tabular}

Table 2: Distribution (frequency) of bacterial isolates from newborns with clinically suspected cases of septicaemia.

\begin{tabular}{|c|c|c|}
\hline $\begin{array}{l}\text { Isolate gram positive } \\
\text { cocci }(n=47)\end{array}$ & $\begin{array}{l}\text { Distribution } \\
\text { (frequency) }\end{array}$ & $\begin{array}{l}\text { Percentage } \\
(\%)\end{array}$ \\
\hline $\begin{array}{l}\text { Coagulase negative } \\
\text { staphlylococcus }\end{array}$ & 32 & 68 \\
\hline Staphyl occus aureus & 7 & 21 \\
\hline $\begin{array}{l}\text { Methicillin resistant } \\
\text { Staphylcoccus aureus }\end{array}$ & 3 & 6 \\
\hline Enterococcus & 3 & 6 \\
\hline Steptococcus & 1 & 2 \\
\hline Gram positive bacilli & 1 & 2 \\
\hline
\end{tabular}


Table 3 and 4, show the comparative sensitivity percentage of gram negative and gram positive isolates to commonly use antimicrobial drugs. Most of the gram positive and gram negative isolates showed resistance to commonly used drugs like ampicillin, ceftriaxone and ceftazidime. None of the isolate was sensitive to ampicillin. Among sensitivity pattern in gram negative isolates there was a high degree of sensitivity to drugs like Polymyxin b (77.8\%) and tigecycline (72\%) and among gram positive to vancomycin $(90 \%)$ and linezolid $(87 \%)$. None of the MRSA strain was resistant to vancomycin.

Table 3: Comparative sensitivity percentage of gram negative bacteria to different antimicrobial agent.

\begin{tabular}{|c|c|c|c|c|c|c|c|c|c|c|c|c|}
\hline & $\mathbf{N}$ & $\mathbf{A M} \mathbf{P}^{1}$ & $\mathrm{CTR}^{2}$ & $\mathbf{C Z}^{3}$ & PIT $^{4}$ & IMP ${ }^{5}$ & GEN $^{6}$ & $\mathbf{A K}^{7}$ & $\mathrm{CIP}^{8}$ & $\mathbf{L E}^{9}$ & $\mathrm{~PB}^{10}$ & TGC $^{10}$ \\
\hline Kliebsiella & 33 & 0 & $\begin{array}{l}6 \% \\
(1)\end{array}$ & $\begin{array}{l}3 \% \\
(1)\end{array}$ & $\begin{array}{l}3 \% \\
(1)\end{array}$ & $\begin{array}{l}57 \% \\
(25)\end{array}$ & $\begin{array}{l}6 \% \\
(2)\end{array}$ & $\begin{array}{l}6 \% \\
(2)\end{array}$ & $\begin{array}{l}48 \% \\
(16)\end{array}$ & $\begin{array}{l}60 \% \\
(20) \\
\end{array}$ & $\begin{array}{l}87 \% \\
(29) \\
\end{array}$ & $\begin{array}{l}87 \% \\
(29)\end{array}$ \\
\hline Ecoli & 14 & 0 & $\begin{array}{l}21 \% \\
(3)\end{array}$ & $\begin{array}{l}7 \% \\
(1)\end{array}$ & $\begin{array}{l}21 \% \\
(3)\end{array}$ & $\begin{array}{l}71 \% \\
(10)\end{array}$ & $\begin{array}{l}35 \% \\
(5)\end{array}$ & $\begin{array}{l}28 \% \\
(4)\end{array}$ & $\begin{array}{l}21 \% \\
(3)\end{array}$ & $\begin{array}{l}21 \% \\
(3)\end{array}$ & $\begin{array}{l}78 \% \\
(11)\end{array}$ & $\begin{array}{l}64 \% \\
(9)\end{array}$ \\
\hline Acinetobacter & 8 & 0 & 0 & 0 & $\begin{array}{l}13 \% \\
(1)\end{array}$ & $\begin{array}{l}50 \% \\
(4)\end{array}$ & 0 & 0 & $\begin{array}{l}13 \% \\
(1)\end{array}$ & $\begin{array}{l}85 \% \\
(7)\end{array}$ & $\begin{array}{l}87 \% \\
(7)\end{array}$ & $\begin{array}{l}75 \% \\
(6)\end{array}$ \\
\hline Enterobacter & 7 & 0 & $\begin{array}{l}14 \% \\
(1)\end{array}$ & 0 & $\begin{array}{l}28.50 \% \\
(2)\end{array}$ & $\begin{array}{l}57 \% \\
(4)\end{array}$ & $\begin{array}{l}14 \% \\
(1)\end{array}$ & $\begin{array}{l}28.50 \% \\
(2)\end{array}$ & $\begin{array}{l}28.50 \% \\
(2)\end{array}$ & $\begin{array}{l}57 \% \\
(4)\end{array}$ & $\begin{array}{l}57 \% \\
(4)\end{array}$ & $\begin{array}{l}86 \% \\
(6)\end{array}$ \\
\hline Citrobacter & 7 & 0 & $\begin{array}{l}28 \% \\
(2)\end{array}$ & 0 & $\begin{array}{l}28 \% \\
(2)\end{array}$ & $\begin{array}{l}42 \% \\
(3)\end{array}$ & $\begin{array}{l}42 \% \\
(3)\end{array}$ & $\begin{array}{l}42 \% \\
(3)\end{array}$ & $\begin{array}{l}57 \% \\
(4)\end{array}$ & $\begin{array}{l}85 \% \\
(6)\end{array}$ & $\begin{array}{l}71 \% \\
(5)\end{array}$ & $\begin{array}{l}100 \% \\
(7)\end{array}$ \\
\hline Psedomonas & 4 & 0 & $\begin{array}{l}25 \% \\
(1)\end{array}$ & $\begin{array}{l}25 \% \\
(1)\end{array}$ & $\begin{array}{l}100 \% \\
\text { (4) }\end{array}$ & $\begin{array}{l}100 \% \\
\text { (4) }\end{array}$ & $\begin{array}{l}50 \% \\
(2)\end{array}$ & $\begin{array}{l}25 \% \\
(3)\end{array}$ & $\begin{array}{l}75 \% \\
(3)\end{array}$ & $\begin{array}{l}75 \% \\
(3)\end{array}$ & $\begin{array}{l}75 \% \\
(3)\end{array}$ & $0 \%$ \\
\hline
\end{tabular}

Penicillin (AMP); Ceftriaxone (CTR); Cephalosporin (CZ); B lactem inhibiter (PIT); Carbepenum (IMP), Aminoglycoside (GEN,AK), Quinolones (CIP,LE), Lipopeptides (PB), Glycycline (TGC).

1 Ampicillin; 2 Ceftrixone; 3 Ceftazidime; 4 Piperacillin tazobactem; 5 Imipenum; 6 Gentamycin; 7 Amikacim; 8 Ciprofloxacian,; 9 Levofloxacin; 10 Polymxin b; 11 Tigecyline.

Table 4: Comparative sensitivity percentage of gram positive bacteria to different antimicrobial agent.

\begin{tabular}{|lllllllllll|} 
& N & AMP & CTR & IMP & GEN $^{5}$ & LE $^{8}$ & TGC $^{10}$ & TEI $^{11}$ & VA $^{12}$ & LZ $^{13}$ \\
\hline CoNS & 32 & 0 & $34 \%(11)$ & $6 \%(2)$ & $56 \%(18)$ & $47 \%(15)$ & $84 \%(27)$ & $84 \%(27)$ & $91 \%(29)$ & $84 \%(27)$ \\
\hline Staph aureus & 7 & 0 & $14 \%(3)$ & $28.50 \%(2)$ & $57 \%(4)$ & $43 \%(3)$ & $86 \%(6)$ & $71 \%(5)$ & $86 \%(6)$ & $71 \%(5)$ \\
\hline MRSA & 3 & 0 & 0 & 0 & 0 & $67 \%(2)$ & $100 \%(3)$ & 0 & $100 \%(3)$ & $67 \%(2)$ \\
\hline Enterococcus & 3 & 0 & 0 & 0 & $100 \%(3)$ & $100 \%(3)$ & $100 \%(3)$ & $67 \%(2)$ & $67 \%(2)$ & $100 \%(3)$ \\
\hline Streptococcus & 1 & 0 & $100 \%(1)$ & 0 & $100 \%(1)$ & $100 \%(1)$ & $100 \%(1)$ & $100 \%(1)$ & $100 \%(1)$ & $100 \%(1)$ \\
\hline GPB & 1 & $\mathrm{R}$ & 0 & 0 & 0 & 0 & 0 & 0 & $100 \%(1)$ & $100 \%(1)$ \\
\hline
\end{tabular}

Penicillin (AMP); Ceftriaxone (CTR); Carbepenum (IMP), Aminoglycoside (GEN); Quinilones (LE), Glycline (TGC) Glycopeptides (TEI, VA, LZ).

1 Ampicillin; 2 Ceftrioxone; 4 Imipenum; 5 Gentamycin; 8 Levofloxacin; 10 Tigecyline; 8 Teicoplanin; 12 Vancomycin; 13 Linezoleid.

\section{DISCUSSION}

Blood infection is the main cause of neonatal mortality in the neonatal intensive care units7.The uncertainty surrounding the clinical approach to treatment of neonatal septicemia can be minimizes by periodic epidemiological surveys of aetiological agents and their antibiotic sensitivity patterns leading to recognition of the most frequently encountered pathogens in a particular geographical area. For effectual management of septicemia cases, study of bacteriological profile along with antimicrobial sensitivity pattern plays a noteworthy role.

In the present study the overall sepsis rate was $10.3 \%$ (124/1200), which is quite low compared to other studies. $^{2,3,8,9}$ Low blood culture isolation rate in this study might be due to several reasons, e.g. administration of antibiotics before blood collection either to the mother or to the baby or the possibility of infection with viruses, funguses or anaerobes which cannot be ruled out. ${ }^{10,11}$ Some of these patients may have metabolic disease inappropriate blood sampling or culture techniques. ${ }^{12-14} \mathrm{~A}$ negative blood culture does not exclude sepsis and about $26 \%$ of all neonatal sepsis could be due to anaerobes..$^{15}$ It is possible that many anaerobes were being missed in this study. Chow et al demonstrated the significance of anaerobes in neonatal sepsis. ${ }^{16}$ In a recent Indian study, anaerobes were isolated in $6.6 \%$ cases of neonatal blood cultures. ${ }^{17}$ However the feasibility, logistics and cost effectiveness of routine anaerobic cultures for neonatal sepsis needs to be explored. Zaidi et al reported that anaerobic cultures are rarely helpful in majority of 
paediatric patients and usually show positive results only in clinical settings associated with anaerobic infections. ${ }^{18}$

The pathogens most often implicated in neonatal sepsis in developing countries differ from those seen in developed countries. Overall Gram negative organisms are more common and are mainly represented by Klebsiella, E.coli and Pseudomonas. Of the Gram positive organisms CoNS and S.aureus are most commonly isolated. ${ }^{19}$

In the present study, gram negative and gram positive septicemia was encountered in $(62 \%)$ and $(38 \%)$ of the culture positive cases. A recent study conducted in Karnataka reported $70.5 \%$ neonatal septicemia caused by gram -negative isolates. ${ }^{20}$ Out of the gram negative isolates Klebsiella pneumonia was found to be predominant pathogen $(42.8 \%)$. K. pneumonia was reported as a predominant pathogen in NNPD Report 2002-2003 and by Mane et al and Mustafa et al from India and by Irregu et al from Nigeria. ${ }^{21-24}$ Predominance of $K$. pneumonia as the causative agent may be due selective pressure of antimicrobial agents so that resistant organisms tend to colonize and proliferate in the neonates.

Other Gram negative organisms isolated were E. coli (18.10\%), Acinetobacter species (10.3\%), Enterobacter (9\%) and Pseudomonas species $(5.10 \%)$. Huang et al described Acinetobacter baumannii as nosocomial pathogens in adults, being also responsible for infections in neonates hospitalized in ICU, causing pneumonia. It is ubiquitous microorganism implicated in a number of outbreaks in ICUs. ${ }^{25}$

Among gram positive isolates CoNS (57.4\%) was the most common pathogen isolated from gram positive isolates. CoNS as a predominant source of infection in NICU has been reported in studies of United States and Asian countries. ${ }^{26,27}$ In Europe, most of the nosocomial infections $(76 \%)$ were caused by gram positive bacteria, with CoNS being the most frequently occurring pathogen even in Brazil. ${ }^{28,29}$

S. aureus was isolated from $(21.2 \%)$ of gram positive organisms and was the next common pathogen following CoNS and S. aureus as a major pathogen of neonatal septicemia has been reported by Karthikeyen et al. ${ }^{30}$ These findings have implications for therapy and infection control .It can survive in the environment for a relatively long time and is fairly widely distributed in the hospital environment and therefore has the potential for being transmitted from the environment to the patients through practices that breach infection control measures. $S$. aureus is the most common pathogen causing pustulosis and cellulitis in neonates. The presence of virulence factors such as the Panton-Valentine leucocidin is thought to contribute to the pathogens ability to cause skin and soft tissue infections. In addition to underdeveloped epidermis and frequent breeches in skin integrity due to intravenous catheters, blood draws and heel pricks place preterm neonates at risk of infection.

Antibiotic resistance is today a global problem Reports of multi-resistant bacteria causing neonatal sepsis in developing countries are increasing. The wide availability of the over the counter antibiotics and the in appropriate use of broad -spectrum antibiotics in the community may explain this situation. It is difficult to compare antibiotic resistance between countries because the epidemiology of neonatal sepsis is extremely variable.

Antibiotic susceptibility pattern was studied for all isolates causing neonatal sepsis. The analysis of drug sensitivity pattern showed that, among gram negative isolates, maximum numbers were sensitive to Polymyxin $(77.8 \%)$ and tigecycline $(72 \%)$ and gram positive were sensitive to vancomycin (90\%) and linezolid (87\%). Resistance was observed against commonly used antibiotics such as penicillin ampicillin, amoxiclav, and ceftazidime. The greater prevalence to commonly used antibiotics has been reported by other studies. ${ }^{1,3}$

In the present study, Klebsiella species revealed high susceptibility to polymyxin (87\%) and tigecycline (87\%) and $E$. coli to polymyxin $(78 \%)$ and imipenem $(78 \%)$. They exhibited a greater degree of resistance to aminoglycosides and fluoroquinolones; this could be due to indiscriminate use of these drugs in community. Among Gram positive isolates CoNS was sensitive to vancomycin $(91 \%)$ and linezolid $(84 \%)$ and S. aureus to vancomycin $(86 \%)$ and tigecycline $(86 \%)$. All of the MRSA strains were sensitive to vancomycin.

We did not distinguish between community and hospital acquired infections for analyzing our results. Being a retrospective study of microbiological records, correlation with neonatal mortality and morbidity was not possible. Inclusion of this data would have definitely enhanced utility of this.

\section{CONCLUSION}

It is evident from this study that Gram negative organisms (Klebsiella, E. coli). CoNS and S. aureus are the leading cause of neonatal sepsis in this study, and most of them are resistant to multiple antibiotics. An alarming finding of this study is the high proportion of organisms resistant to commonly used antibiotics, which could be explained due to indiscriminate use of these drugs in community. So authors suggest an effective infection control programme, regular antibiotic susceptibility surveillance and evaluation, and the enforcement and periodic review of the antibiotic policy of the hospital as well as encouragement of rational antibiotic use so as to reduce rate of acquiring nosocomial infections and development of bacterial resistance. Furthermore, we advise that health education be provided to the public on the dangers of indiscriminate use of antibiotics, which is currently considered to be a 
menace in our society and which has been responsible for the ineffectiveness of most commonly used antibiotics such as penicillin and ampicillin, as observed in our study.

\section{Funding: Research committee of SRHU University Conflict of interest: None declared}

Ethical approval: The study was approved by the Institutional Ethics Committee

\section{REFERENCES}

1. Tsering DC, Chanchal L, Pal R. Bacteriological profile of septicaemia and the risk factor in neonates and infants in Sikkim. Journal of global infectious diseases. 2011;3(1):42-5.

2. Jain A, Awasthi AK, Kumar M. Etiological and antimicrobial susceptibility profile of nosocomial blood stream infections in a neonatal intensive care unit. Indian journal of medical microbiology. 2007;25:299-300.

3. Kumbar GD, Ramachandran VG, Gupta P. Bacteriological analysis of blood culture isolates from neonates in tertiary care hospital in India. Journal of health population and nutrition. 2002;20:343-7.

4. Ducel G, Fabry J, Nicolle L. Prevention of hospital acquired infections. A Practical Guide. $2^{\text {nd }}$. Geneva,Switzerland. World Health Organisation. 2002.

5. Payne NR, Carpenter JH, Badger GJ, Horbar JD, Rogowski J. Marginal increase in cost and excess length of stay associated with nosocomial bloodstream infection in surviving very low birth infants. Pediatrics. 2004;114(2):348-55.

6. Pennysylvania,USA. Clinical Laborotory and Standards Institutes;2011. Performance Standards for Antimicrobial Suseptibility Testings ;Twenty first informational supplement.M100-S21.

7. Robinson D, Kumar P, Cadichon S. Neonatal Sepsis in the Emergency Department. Pediatr Emerg Med. 2008;9(3):160-8.

8. Ahmed AS, Chowdary MA, Hoque M, Darmstadt GL. Clinical and bacteriological profile of neonatal septicaemia in a tertiary level pediatric hospital in Bangladesh. Indian Pediatri. 2002;39(11):1034-9.

9. Mathur M, Shah H, Dixit $K$, Khambadkone S, Chakrapani A, Irani S. Bacteriological profile of neonatal septicaemia cases (for the year 1990-91). J Post grad Med. 1994;40(1):18-20.

10. Loureiro MM, Moraes BA, Quadra MRR, Pinheiro GS, Asensi MD. Study of multi drug resistant microorganisms isolated from blood cultures of hospitalized newborns in Rio de janerio city,Brazil. Brazil J Microbiol. 2002;33(1):73-8.

11. Agnihotri N, Kaistha N, Gupta V. Antimicrobial susceptibility of isolates from neonatal septicaemia. Jpn J Infect Dis. 2004;57(6):273-5.

12. Wasant $\mathrm{P}$, Srisimsapn C, Liammong-kolkul S, Svasti J. Urea cycle disorders in Thai infants: a report of 5 cases. J Med Ass Thailand. 2002;85(suppl 2):S720-31.

13. Lund AM, Christensen E, Skovby F. Diagnosis and acute treatment of inborn metabolic disease in infants. Ugeskrift for Laeger. 2002;164(48);5613-9.

14. Bansal S, Jain A, Agarwal J, Malik GK. Significance of caugulase negative staphylococci in neonates with late onset septicaemia. Indian J Pathol Microbiol. 2004;47:586-8.

15. Shresta P, Das BK, Bhatta NK, Jha DK, Das B, Setia A,et al. Clinical and bacteriological profile of blood culture positive sepsis in newborns. J Nepal Paediatr Soc. 2007;27(2):64-7.

16. Chow AW, Leake RD, Yamauchi T, Anthony BF, Guze LB. The significance of anaerobes in neonatal septicaemia :analysis of 23 cases and review of the literature. Pediatrics. 1974;54:736-45.

17. Thomas M, Padmini B, Srimathi G, Sunderrajan V, Raju BA. Microbiological profile of neonatal sepsis in Coimbatore .Indian J Pediatr. 1999;66:11-4.

18. Zaidi AKM, Knaut AL, Mirrett S, Reller LB.Value of routine of anaerobic blood culture for pediatric patients. J Pediatr. 1995;127:263-8.

19. Vergnano S, Sharland MWP, Mwansambo C. Health PT, Neonatal sepsis:An international perspective. Arch Dis Child Foetal Neonatal Ed. 2005;90:220-4.

20. Rajendraprasad BP, Basavaraj KN, Antony B. Bacterial spectrum of neonatal septicaemia with their antibiogram with refrence to various predisposing factors in a tertiary care hospital in southern India. Ann Trop Med Public Health. 2013;6:96-9.

21. Report of the National Neonatal Database .Report 2002 2003.NNPD Network. Assessed online from 2010.

22. Mane AK, Nagdeo NV, Thombare VR. Study of neonatal septicaemia in a tertiary care hospital in rural Nagpur. J Recent Advances Appl Sci. 2010;25:19-24.

23. Mustafa M, Ahmed SL. Bacteriological profile and antibiotic susceptibility patterns in neonatal septicaemia in view of emerging drug resistance. J Med Allied Sci. 2014;4:2-8.

24. Iregbu KC, Elegba OY, Babaniyi IB. Bacteriological profile of neonatal septicaemia in a tertiary care hospital in Nigeria .Afr Health Sci. 2006;66:151-4.

25. Huang YC, Su LH, Wu TL, Leu HS, Hsieh WS, Chang TM, et al. Outbreak of Acinetobacter baumanii bacteremia in a neonatal intensive care unit: clinical implications and genotyping analysis. Pediatr Infect Dis J. 2002;21(12):1105-9.

26. Stoll BJ, Hansen N, Fanaroff AA, Wright LL, Carlo WA, Ehrenkranz RA, et al. Late-onset sepsis in a very low birth weight neonates :the experience of the NICHD Neonatal Research Network. Pediatrics. 2002;110(2):285-91.

27. Tiskumara R, Fakhree SH, Liu CQ, Nuntnarumit P, Lui KM, Hammoud M, et al. Neonatal infections in 
Asia. Arch of Dis child fetal neonatal edition. 2009;94(2):144-8.

28. Urrea M, Iriondo M, Thio M, Krauel X, Serra M, LaTorre C, et al. A prospective incidence study of nosocomial infections in a neonatal care unit. American journal of Infection Control. 2003;31(8):505-7.

29. Kawagoe JY, Segre CAM, Pereira CR, Cardoso MFS, Silva CV, Fukushima JT. Risk factors for nosocomial infection in critically ill newborn: A 5 year prospective cohort study. American Journal Of Infection Control. 2001;29(2):109-14.
30. Karthikeyen G, Premkumar K. Neonatal sepsis: Staphylococcus as a predominant pathogen. Indian J Pediatr. 2001;68:715-7.

Cite this article as: Pandita N, Wasim S, Bhat NK, Chandra V, Kakati B. Identification of the bacterial isolates in neonatal septicaemia and their antimicrobial susceptibility in a tertiary care hospital in Uttarakhand, India: a retrospective study. Int J Contemp Pediatr 2016;3:200-5. 